\title{
A Clinicopathological Study of Gall Bladder Disorders
}

\section{Authors \\ Dr Amit Kumar Gupta ${ }^{1}$, Dr Khwaja Nasim Ahmad ${ }^{2}$, Dr A.Z. Malik $^{3}$ \\ ${ }^{1} 2^{\text {nd }}$ Year Surgery Resident, ${ }^{2}$ Associate Professor, ${ }^{3}$ Professor Department of Surgery, Katihar Medical College Katihar Bihar, India}

\section{Introduction}

- Gall bladder diseases has worldwide distribution with variable incidence amongst different countries.

- Gall stone disease is one of the most common problems affecting digestive tract, with higher incidence amongst females (female to male ratio- 3:1).

- Majority of the patients with cholelithiasis present with chronic cholecystitis with complaint of recurrent attacks of abdominal pain.

- Other common presentation is acute calculus cholecystitis with empyema

- Management modalities initially involves clinical and ultrasonographic (USG) diagnosis, followed by conservative medical management or modern surgical interventions by laparoscopy and endoscopy.

\section{Aims \& Objectives}

Our study aims

1. To look at the demographics (age and sex incidence) and various clinical presentations.

2. To analyse the relation of gall bladder diseases (with or without stones).
3. Role of various diagnostic proceduresUSG findings, gross and histopathological findings.

4. To study treatment modalitiesconservative and surgical.

5. To study pathological finding of the removed gall bladder.

\section{Material \& Methods}

- This is a prospective study conducted in 65 patients with clinical features suggestive of cholecystitis or had a definitive diagnosis of cholelithiasis or other gallbladder disorder, who were admitted in the surgical wards of KATIHAR MEDICAL COLLEGE from January 2018 to JULY2018

- The cases were evaluated by a detailed history (age, sex, parity, socio-economic status, nature \& duration of symptoms, past $\mathrm{h} / \mathrm{o}$ similar complaints, any co-morbid illnesses) and physical examination

- All patients were investigated with CBC,LFT, $\mathrm{kFT}$, blood sugar, chest X-ray. USG was done in all cases whereas $\mathrm{CT}$ scan \& MRCP in selected cases.

- Informed consent obtained from all patients. 
- Acute conditions- conservative management was done (Nil per month, IV fluid, analgesics, and antibiotics, ryle's tube aspiration ).

- Chronic conditions- operative measures (open or laparoscopic cholecystectomy).

- The type of operation done, and approach used, intra operative findings were recorded.

- Post cholecystectomy, the removed gallbladder was sent for histopathological examination and the bile for bacteriological analysis.

- Routine postoperative care was given \& monitoring was done to note any complications.

- The time during of the patient stay in the hospital and associated complication of the operative procedure were recorded.

\section{Results}

- In our study we have prospectively analysed the clinical \& pathological features of gall bladder diseases over a period of6 MONTH with the following findings:-

- Higher incidence of gall bladder disorders was seen among females (69.2\%) as compared to males (30.7\%), multiparous $(52.3 \%)$, with age distribution commonly seen in $4^{\text {th }}$ decade $(40 \%)$ followed by $5^{\text {th }}$ decade $(35.3 \%)$.

- Most common clinical symptom was pain abdomen $(72 \%)$, dyspepsia $(63.7 \%)$ and vomiting (54.7\%).

- Most common disorder in our study was chronic cholecystitis (58.4\%) followed by cholelithiasis (16.9\%). On USG findings, $87.6 \%$ cases were diagnosed as cholecystitis with cholelithiasis and CBD was found normal in $72.3 \%$ cases.

- Cholecystectomy was done in $89.17 \%$ (58) cases, laparoscopic cholecystectomy in $72.3 \%$. Histopathological findings showed maximum evidence of chronic cholecystitis (87.9\%).

- Duration of postoperative stay was shorter in laparoscopic cholecystectomy group with a mean duration of 2.6 days in 47 patients as compared to open cholecystectomy in 11 patients (5.9).

\section{Table - 1}

Relation to Sex ( $n=65$ )- In our study, $69.2 \%$ cases were females

\begin{tabular}{|c|c|c|}
\hline SEX & NO. OF CASES & PERCENTAGE \\
\hline Male & 20 & $30.7 \%$ \\
\hline Female & 45 & $69.2 \%$ \\
\hline
\end{tabular}

\section{Table - 2}

Age \& Sex Distribution

Maximum no. of cases $(40 \%)$ were seen in $4^{\text {th }}$ decade, followed by $35.3 \%$ in $5^{\text {th }}$ decade

\begin{tabular}{|l|c|c|c|c|}
\hline Age in years & Male & Female & Total & Percentage \\
\hline $21-30$ & 1 & 3 & 4 & $6 \%$ \\
\hline $31-40$ & 8 & 18 & 26 & $40 \%$ \\
\hline $41-50$ & 8 & 15 & 23 & $35.3 \%$ \\
\hline $51-60$ & 2 & 5 & 7 & $10.7 \%$ \\
\hline $61-70$ & 1 & 4 & 5 & $7.6 \%$ \\
\hline Total & 20 & 45 & 65 & \\
\hline
\end{tabular}


Distribution According to Symptoms

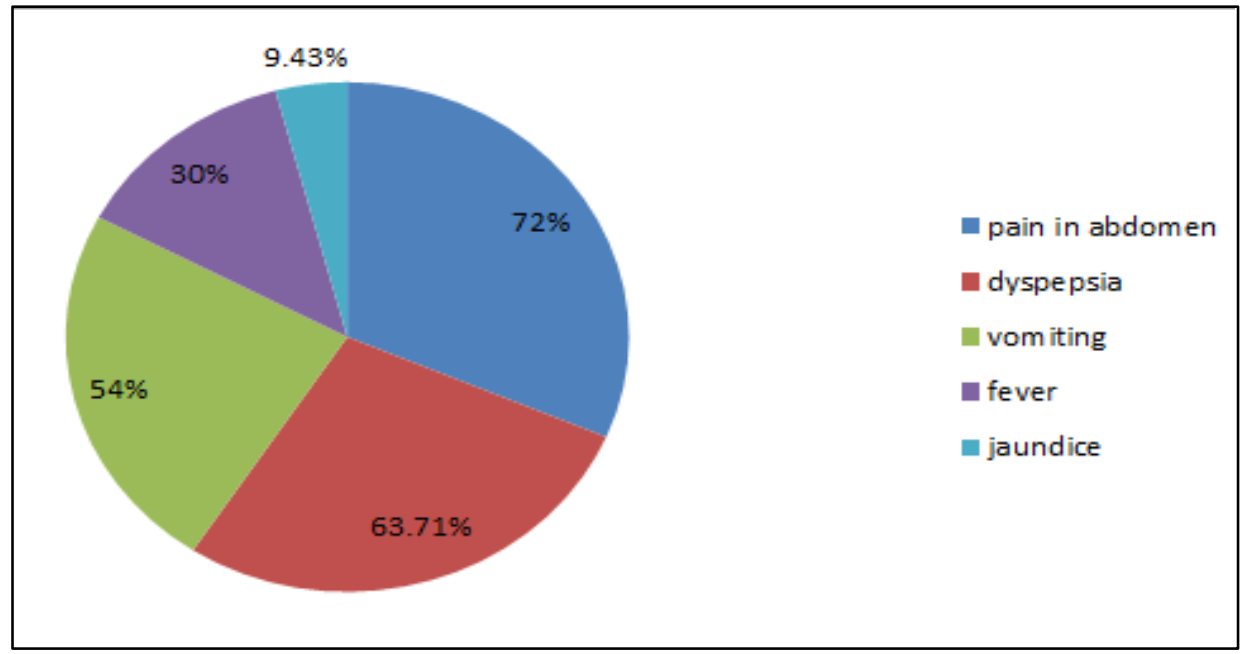

Incidence According to the type of Disorder $(n=65)$

Most common disorder in our study was chronic cholecytitis $(58.4 \%)$

\begin{tabular}{|l|c|c|}
\hline Gall Bladder Disorder & Number & Percentage \\
\hline Acute calculous cholecystitis & 8 & $12.3 \%$ \\
\hline Cholelithiasis & 3 & $4.61 \%$ \\
\hline Acute acalculous cholecystitis & 1 & $1.5 \%$ \\
\hline Cholelitiasis with choledocholelithiasis & 11 & $16.9 \%$ \\
\hline Chronic cholecysytitis & 38 & $58.4 \%$ \\
\hline CAGB with metastasis & 3 & $4.61 \%$ \\
\hline CAGB without metastasis & 1 & $1.5 \%$ \\
\hline
\end{tabular}

Relation with Parity (n=45) Maximum no. of patients were multipara (52.3\%)

\begin{tabular}{|c|c|c|}
\hline Parity & No Of Patients & Percentage \\
\hline Nullipara & 1 & $2.2 \%$ \\
\hline 1 & 3 & $6.6 \%$ \\
\hline 2 & 7 & $15.5 \%$ \\
\hline$>3$ & 34 & $52.3 \%$ \\
\hline
\end{tabular}

USG Findings $(n=65) 87.6 \%$ cases were diagnosed as cholecystitis with cholelithiasis, CBD was found normal in $72.3 \%$ cases

\begin{tabular}{|l|c|c|}
\hline \multicolumn{1}{|c|}{ 1. Gall Bladder } & No. of Cases & Percentage \\
\hline Cholecystitis with cholelithiasis & 57 & $87.6 \%$ \\
\hline Acalculous cholecystitis & 1 & $1.5 \%$ \\
\hline Cholelithiasis & 3 & $4.6 \%$ \\
\hline ? GB malignancy & 4 & $6.1 \%$ \\
\hline 2. COMMON BILE DUCT & & \\
\hline Normal & 47 & $72.3 \%$ \\
\hline Dilated & 7 & $10.7 \%$ \\
\hline Stone & 11 & $16.9 \%$ \\
\hline
\end{tabular}

Type of Treatment $(n=65)$ In ours study laparoscopic cholecystectomy was done in $72.3 \%$ cases.

\begin{tabular}{|l|c|c|}
\hline Treatment & No. Of Cases & Percentage \\
\hline CONSERVATIVE & 7 & $10.7 \%$ \\
\hline OPERATIVE :- & & \\
\hline 1. Open cholecystectomy & 9 & $13.8 \%$ \\
\hline 2. Lap. Cholecystectomy & 47 & $72.3 \%$ \\
\hline 3. Lap. Converted to open cholecystectomy & 2 & $3.07 \%$ \\
\hline
\end{tabular}


Histopathological Findings $(n=58) 87.9 \%$ cases were of chronic cholecystitis

\begin{tabular}{|l|c|c|}
\hline HISTOPATHOLOGICAL FINDING & Cases & Percentage \\
\hline 1. Chronic cholecystitis & 51 & $87.9 \%$ \\
\hline 2. Acute cholecystitis & 2 & $3.4 \%$ \\
\hline 3. Well differentiated adenocarcinoma & 3 & $3.4 \%$ \\
\hline 4. Normal histology & 2 & $5.1 \%$ \\
\hline
\end{tabular}

\section{Bacteriology of Bile \& Nature of Organism}
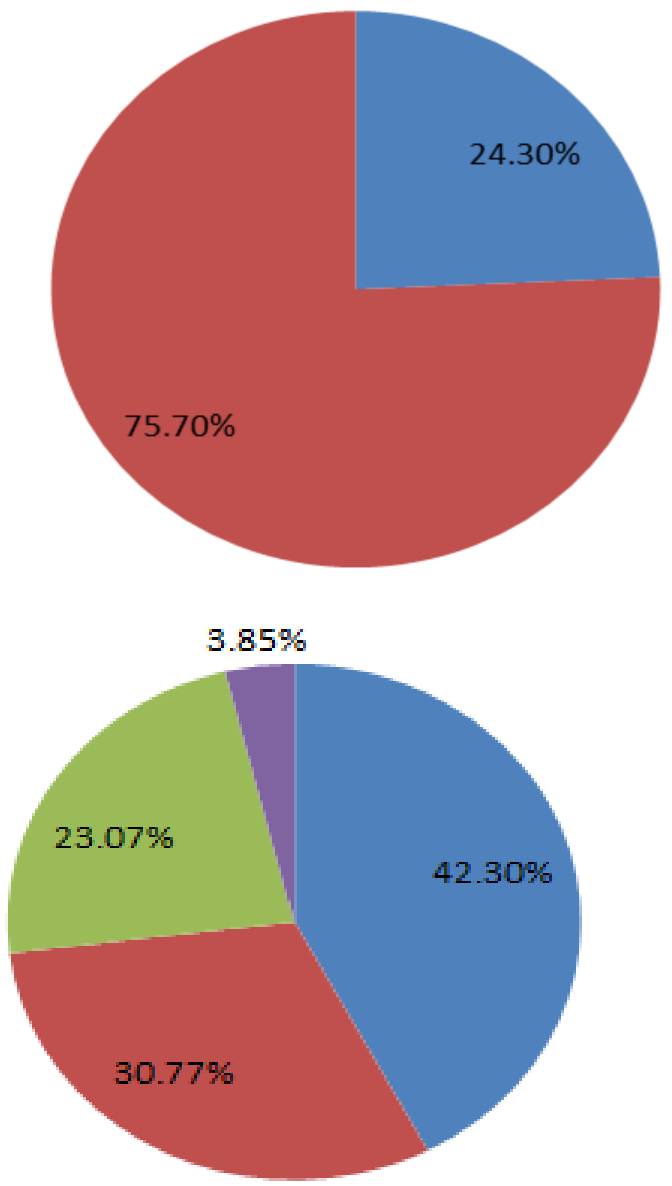

E. coli

Kle bsie lla

S. aureus

Pseudomonas

Postoperative Hospital Stay- Mean duration of stay in hospital was lesser in cases who underwent laparoscopic cholecystectomy (2.6 days) as compared to open cholecystectomy

\begin{tabular}{|l|c|c|}
\hline Type of operation & No. of patients & Mean duration of stay ( in days) \\
\hline Laparoscopic cholecystectomy & 47 & 2.6 \\
\hline Open cholecystectomy & 11 & 5.9 \\
\hline
\end{tabular}

\section{Discussion}

- In our study, gall bladder disorders were found to be more common in females as compared to males with a male to females as compared to males with a ratio of $1: 3.2$ similar to other studies $(1: 2.8)$ and $(1: 3) .^{(1-2)}$

- Out of 65 cases studied, $75.3 \%$ cases were diagnosed as chronic cholecystitis. Majority of the patients represented with complaint of pain abdomen in the right hypochondrium.
- $89.17 \%$ of cases underwent surgery for the removal of diseased gall bladder.

- Histopathological examination confirmed cases of chronic cholecystitis $87.9 \%$.

- Various studies have reported that majority of the non neoplastic gallbladder lesions occurred in $4^{\text {th }} \& 5^{\text {th }}$ decades, ${ }^{(3-4)}$ which is similar to our studies.

- Chronic cholecystitis usually occurs after repeated episodes of acute cholesystitis and 
may lead to a variety of complications such as gangrene, perforation or fistula formation. ${ }^{(5)}$

- Therefore, routine investigations and proper diagnosis seems mandatory to help avoid the complications associated with gall bladder lesions.

\section{Conclusion}

The incidence of chronic calculous cholecystitis was found to be $76.3 \%$ with a female preponderance $(69.2 \%)$. Our study strongly recommends routine USG and histopathological examination of all cholecystectomy specimens for detection of various variants of gall bladder disorders which helps in their treatment and prognosis.

\section{References}

1. Singh AP, Sharma P, Chhari AS, Gaharwar APS. Clinicopathological study of gall bladder disorders. International Journal of Surgery.2016; 3(3): 1213-7

2. Sharma I, Choudhary D. Histopathological patterns of gall bladder diseases with special reference to incidental cases: a hospital based study. International Journal of Research in Medical Sciences. 2015; 3(12): 3553-7

3. Ghosh SK, Das KN, Bose D, Raj B, Sadhu BN, Roy D. Aetiopathogenesis of chronic cholecystitis in gangetic West Bengal- a study of 300 cases. Ind J Surg.1995; 57: 313-6

4. Selvi RT, Sinha P, Subramaniam PM, Konapur PG, Prabha CV. A Clinicopathological study of acute cholecystitis with special reference to analysis of cholelithiasis. IJABMR. 2011; 2: $68-72$

5. Sharma P, Agrawal M, Chanchlani R, Krsihnanand RP. A study of epidemiology of gallbladder carcinoma and cholelithiasis at a tertiary institute in central India. JEMDS. 2014; 3 (15): 4023-8
6. Rakesh BH, Rajendra GC. A prospective clinicopathological study of 50 cases of chronic calculous cholecystitis in the local population. JEMDS. 2013; 2(35): 6706-16. 